\title{
Clinical Comparison of 5\% Potassium Nitrate and $10 \%$ Strontium Chloride Toothpastes in Alleviating Dentin Hypersensitivity Following Manual Scaling: A Pilot Study
}

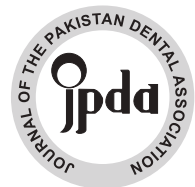

Anam Zahid Kiani ${ }^{1}$

Sobia Hassan ${ }^{2}$

Talha Rafiq ${ }^{3}$

\author{
BDS, MSc \\ BDS, FCPS \\ BDS
}

OBJECTIVE: The objective of this study was to compare the efficacy of dentifrices containing potassium nitrate and strontium chloride in reducing dentinal sensitivity pain.

METHODOLOGY: A pilot study was conducted in Islamic International Dental Hospital Islamabad, Pakistan (Duration two weeks). Forty participants were selected, aged between 18-40 years, having dentin hypersensitivity with the minimum score of 4 on Visual Analog Scale. Participants were randomly allocated with dentifrices containing 5\% w/w potassium nitrate and $10 \% \mathrm{w} / \mathrm{w}$ strontium chloride and were asked to use it for 2 weeks and come back for follow up. Statistically significant correlations were found using the Man Whitney test. A pre-designed proforma was used to acquire information about the patient. Sensitivity was determined with the aid of the Visual Analog Scale.

RESULTS: There was greater reduction in moderate pain from $85.8 \%$ to $71.4 \%$ with strontium chloride and from $84.2 \%$ to $79 \%$ with potassium nitrate.

CONCLUSION: $10 \% \mathrm{w} / \mathrm{w}$ strontium chloride is more effective than the $5 \% \mathrm{w} / \mathrm{w}$ potassium nitrate for the management of dentin hypersensitivity.

KEYWORDS: Toothpastes, Sensitivity, Strontium Chloride, Potassium Nitrate

HOW TO CITE: Kiani AZ, Hassan S, Rafiq T. Clinical comparison of 5\% potassium nitrate and $10 \%$ strontium chloride toothpastes in alleviating dentin hypersensitivity following manual scaling: A pilot study. J Pak Dent Assoc 2021;30(1): 56-60.

DOI: https://doi.org/10.25301/JPDA.301.56

Received: 18 June 2020, Accepted: 14 November 2020

\section{INTRODUCTION}

$\mathrm{D}$ entin Hypersensitivity (DH) has been defined as 'an acute sharp pain of short duration due to exposed dentin, in response to external stimuli that cannot be ascribed to any other form of dental defect and pathology'. ${ }^{1,2}$ It is a painful response to different irritants such as tooth brushing, sweet and/or sour food etc. ${ }^{3}$ It is one of the most commonly encountered clinical problems in routine practice. It has also been considered as a chronic pain condition by some authors. ${ }^{4}$ It is a multi-factorial disease condition caused by enamel loss that could be due to any trauma, gingival recession, erosion and tooth wear. ${ }^{1}$ The prevalence of $\mathrm{DH}$ in the human population is about 10 to $30 \%$, with a female predominance. ${ }^{5}$ Any surface of

1. Registrar, Department of Periodontology, Riphah International University.

2. Assistant Professor, Department of Periodontology, Riphah International University

3. House Officer, Department of Periodontology, Riphah International University.

Corresponding author: "Dr Anam Zahid Kiani” < anamzahid@ gmail.com > tooth can be affected but most common sites are buccal and cervical region of canine and premolars. ${ }^{3} \mathrm{DH}$ can affect any age but usually peaks during the third and fourth decade of life. ${ }^{3}$

It has been proposed that dentin is composed of dentinal tubules that are covered by mineralized structures on crown by enamel or on the root by the cementum. ${ }^{6}$ Exposed dentinal tubules due to gingival recession or loss of enamel, play an important role in dentin hypersensitivity. ${ }^{7,8}$ Many theories have been proposed to explain this phenomenon, including 'Odontoblast Receptor Theory', 'Dentin Innervation Theory' but the most widely accepted theory is the 'Hydrodynamic Theory'. According to this theory, when dentinal tubules come into contact with any stimuli, the dentinal fluid present in tubules tends to move towards the pulp. This movement stimulates the nerve endings in the pulp and that leads to discomfort with pain called dentin hypersensitivity. ${ }^{5}$

Many agents to manage DH are currently being used 
based on two different mechanisms, either by blockage of nerve activity or tubular occlusion. In tubular occlusion approach, most commonly used agents are stannous, strontium, oxalate salts, arginine, silicas, and bioactive glasses. ${ }^{5}$ These agents form salt precipitates on the surface of exposed dentin and inside the dentinal tubules. These precipitates effectively reduce or block the fluid movement in the dentinal tubules and exert a desensitization effect. ${ }^{3}$ The other approach is desensitization of nerve endings, blockage of neural transmission at the pulpal tissues and chemical depolarization of the nerve synapse. ${ }^{4}$ Most common agent used in this approach is potassium nitrate. ${ }^{4}$

Ideally, treatment for dentin hypersensitivity should be quick and simple and should be easily available for patients. Thus, the use of specially medicated toothpastes has been adopted as one of the first lines of treatment. ${ }^{7}$ They are noninvasive and easily available in pharmacies and even in superstores, and according to some studies, they have appreciated cost benefit ratio, in comparison with professional appointments. ${ }^{7}$

Keeping all of these points in mind, we carried out this pilot study to compare the desensitizing efficacy of two commercially available dentrifices with different active ingredients in a hospital setting in Islamabad, as to our knowledge no such study had been carried out regionally.

\section{METHODOLOGY}

This pilot study was based on 40 healthy adults, recruited in the Periodontology department of Islamic International Dental Hospital, Islamabad with the complaint of sensitivity. The sample size was calculated using the WHO Sample Size Calculator with the aid of the parent articles that were used as a template. ${ }^{9,10}$ Patients' sensitivity was confirmed by using a triple syringe of the dental unit after which manual scaling was done by 3 rd year BDS students of Islamic International Dental College. Ethical approval was given by the Ethical Committee of Riphah International University(Reference Number: IIDC/IRC/2018/04/001). The whole process was explained to the patients and signed consent was obtained before the start of procedure.

\section{Inclusion criteria:}

All participants after completing medical history were reviewed by the Principal Investigator before they took part in the study. Participants were selected on the basis of the following criteria:

$>$ Both male and female patients

$>$ Age limit between 18-40 years

D Subjects with good health (with no known systemic diseases)
With Minimum score of 4 on VAS (Visual Analogue Scale)

\section{Exclusion criteria:}

Principal Investigator ruled out participants that were: Already using any desensitizing agent

Currently going through any dental procedure With any appointment of dental treatment during the next 2 weeks that might affect their hypersensitivity.

\section{Proforma:}

The Proforma was based on demographics of participants, checklist for inclusion criteria, procedure done, Visual Analog Scale (VAS)(11) for before and after use with dentifrice, scaling assessment and follow up date. The minimum score on the VAS was "0" and the highest score was set at "10". VAS was categorized in the following manner.
$>0$ "no pain"
0-6 "moderate pain"

6-10 "worst pain"

Participants were asked to have a look at the VAS and encircle the score given on the scale according to intensity of their sensitivity.

\section{Methodology:}

Participants were selected according to our selection criteria. Toothpastes were labeled by the Principal Investigator as "Paste A", that was Sensodyne Original 50mg with $10 \%$ w/w Strontium Chloride, as an active ingredient and, "Paste $\mathrm{B}$ " that was Sensodyne Flouride 50mg with main ingredient that was $5 \% \mathrm{w} / \mathrm{w}$ Potassium Nitrate. Operator had no idea about the pastes. Toothpastes were given by lottery method to the participants. Subjects were given written instructions to use the toothpaste twice a day regularly, using a pea sized amount of toothpaste on medium bristles brush using the Modified Bass brushing technique, which was demonstrated to them on the dental model. All participants were called after two weeks for follow-up.

22 of the patients came back on time for follow-up session, while 18 were contacted via telephone and were sent an image of the VAS and were asked to record their answers. None of the patients were lost to follow-up or dropped out of the study.

\section{Statistical Methodology:}

All the data collected after 2 weeks was entered in SPSS Statistics version 17. The mean of the demographics was calculated and tabulated. The MANN WHITNEY test was applied and results were then tabulated and were prepared for the sensitivity before and after the use of the toothpastes. 
The statistical significance was set at 0.05 .

\section{RESULTS}

40 Patients were evaluated in our study, 21 subjects were provided with paste $\mathrm{A}$ and 19 participants were provided with paste B. Out of 40 subjects, 26 were males $(65 \%)$ and $14(35 \%)$ were females. Majority of patients were between 20-30 age groups. No side effects were reported in any patients enrolled in this study. (See Table 1)

Table 1: Distribution of pastes among participants

\begin{tabular}{|l|l|l|l|}
\hline $\begin{array}{l}\text { Toothpaste } \\
\text { given }\end{array}$ & N & $\begin{array}{l}\text { Mean } \\
\text { Rank }\end{array}$ & P value \\
\hline Paste A & 21 & 25.29 & .004 \\
\hline Paste B & 19 & 15.21 & .004 \\
\hline Total & 40 & & \\
\hline
\end{tabular}

Before commencing the study, 18 patients out of 21 complaint of moderate pain while 3 complaint of worst pain. After use of paste A for the 2 weeks, the 4 patients reported no pain, 15 presented with moderate and 2 with worst pain. (See Table 2)

Table 2: Frequency and percentage of patients before and after use of paste $\mathrm{A}$

\begin{tabular}{|l|cc|cl|}
\hline & \multicolumn{2}{|c|}{$\begin{array}{c}\text { Before use of paste) } \\
\text { Frequency }(\%)\end{array}$} & \multicolumn{2}{|c|}{$\begin{array}{l}\text { After use of paste) } \\
\text { Frequency (\%) }\end{array}$} \\
\hline No pain & 0 & $(0 \%)$ & 4 & $(\mathbf{1 9 \% )}$ \\
\hline Moderate pain & 18 & $(85.8 \%)$ & 15 & $(71.4 \%)$ \\
\hline Worst pain & 3 & $(14.2 \%)$ & 2 & $(9.6 \%)$ \\
\hline Total & 21 & $(100 \%)$ & 21 & $(100 \%)$ \\
\hline
\end{tabular}

At the start of the study, 16 patients out of 19 presented with moderate pain, while 3 presented with worst pain. After use of paste B for the recommended period, 4 patients reported no pain and 15 with moderate pain. No patient reported worst pain. (See Table 3)

Table 3: Frequency and percentage of patients before and after use of paste $B$

\begin{tabular}{|l|cl|cl|}
\hline & \multicolumn{2}{|c|}{$\begin{array}{l}\text { (Before use of paste) } \\
\text { Frequency (\%) }\end{array}$} & \multicolumn{2}{|c|}{$\begin{array}{l}\text { (After use of paste) } \\
\text { Frequency }(\%)\end{array}$} \\
\hline No pain & 0 & $(0 \%)$ & 4 & $(21 \%)$ \\
\hline Moderate pain & 16 & $(84.2 \%)$ & 15 & $(79 \%)$ \\
\hline Worst pain & 3 & $(15.8 \%)$ & 0 & $(0 \%)$ \\
\hline Total & 19 & $(100 \%)$ & 19 & $(100 \%)$ \\
\hline
\end{tabular}

The results obtained were statistically significant as the $\mathrm{p}$ value calculated was 0.004 . According to the frequencies Paste A performed better than Paste B.

\section{DISCUSSION}

Dentin Hypersensitivity (DH), most commonly encountered condition in dental practice, is not only difficult to diagnose but also has an immense effect on the patient's quality of life. ${ }^{3}$ In the light of available studies, DH was found to be present in $10 \%$ to $30 \%$ of the general population. ${ }^{12}$ A study was conducted which revealed that $42 \%$ of DH reported, was in young patients in 18-35 age group. ${ }^{13}$ Another study showed this peak in third and fourth decade of life with female predominance, affecting mostly premolars and molar teeth. ${ }^{14}$ In our study mean age group was 20-30 years with generalized sensitivity and with male predominance.

Currently a lot of treatment regimens are available with many active ingredients. Most of these agents either work by occlusion of dentinal tubules, for example, Strontium based (chloride, acetate) products or by desensitization of nerve ending, for example, Potassium based (chloride, citrate, nitrate) products..$^{15,16}$

An in vitro and in vivo study was conducted on rats to check four different toothpastes in occluding exposed dentinal tubules. Potassium nitrate, strontium chloride and potassium citrate toothpaste containing group were found with less number of open dentinal tubules that was confirmed by the lower permeability of dentin after using desensitizing agents. ${ }^{7}$ In our study strontium chloride was more effective in occluding dentinal tubules than potassium nitrate

Our study compared two commercially available toothpastes containing potassium nitrate and strontium chloride as main active ingredients. Strontium chloride is a protein precipitant and its mechanism of action is the precipitation at the nerve ending and to form a seal to avoid the movement of fluid. ${ }^{3}$ A study by Minkoff and Axelrod as reported by Porto IC et al stated that regular home use of toothpaste containing 10\% strontium chloride proved an efficient means of reducing $\mathrm{DH}^{17}$ which is coherent with our results, showing that $10 \%$ strontium chloride is an effective means for management of $\mathrm{DH}$.

Kishore et al. evaluated the efficacy of desensitizing agents and stated that $10 \%$ strontium chloride showed a marked reduction in dentinal sensitivity whereas $5 \%$ potassium nitrate solution could not. ${ }^{18}$ Our study shows similar results for $10 \%$ strontium chloride and in contrast good results for $5 \%$ potassium nitrate as well.

A randomized, double-blind, placebo-controlled study conducted on potassium nitrate, stated that mouthwash containing a mixture of $\mathrm{KNO}, \mathrm{NaF}$, and $\mathrm{CPC}$ reduced $\mathrm{DH}$ 
and gingival inflammation. ${ }^{12}$ Hodosh stated that topical applications of $1-15 \%$ potassium nitrate or a paste containing $10 \%$ potassium nitrate were effective in minimizing dentin hypersensitivity. ${ }^{19}$ In our study, the dentifrice contained 5\% potassium nitrate which was also effective to some extent but not so much as $10 \%$ strontium chloride. Increasing the percentage of potassium nitrate from $5 \%$ to $10 \%$, might be helpful for management of DH as suggested in the above study.

Another study conducted on potassium nitrate stated that application of potassium nitrate twice daily for two minutes in the form of dentifrice is better than once daily for two minutes. ${ }^{4}$ Our study showed same results with application of $5 \%$ potassium nitrate twice daily for management of $\mathrm{DH}$.

\section{LIMITATION OF STUDY}

This study relied on a proforma only rather than any clinical test to determine dentin hypersensitivity.

Our participants were mostly from Islamabad and Rawalpindi; it is not prudent to assume that our findings are applicable to a broader geographic population.

\section{CONCLUSION}

Under the limitations of our study, $10 \%$ w/w strontium chloride performed adequately in management of dentin hypersensitivity than $5 \% \mathrm{w} / \mathrm{w}$ potassium nitrate.

Since this study was conducted in Islamic International Dental Hospital Islamabad and involved a small number of people, a more comprehensive research is required to be done for better results.

\section{SOURCE OF FUNDING}

There were no funding sources availed for this study.

\section{CONFLICT OF INTEREST}

The authors have stated explicitly that there are no conflicts of interest in connection with this article.

\section{REFERENCES}

1. Alcantara PM, Barroso NFF, Botelho AM, Douglas-de-Oliveira DW, Goncalves PF, Flecha OD. Associated factors to cervical dentin hypersensitivity in adults: a transversal study. BMC Oral Health. 2018;18:155. https://doi.org/10.1186/s12903-018-0616-1

2. Amit B, Shalu BV. Gingival enlargement induced by anticonvulsants, calcium channel blockers and immunosuppressants: A review. IRJP. 2012;3:116-9.

3. Majji P, Murthy KR. Clinical efficacy of four interventions in the reduction of dentinal hypersensitivity: A 2-month study. Ind J Dent Res. 2016;27:477-82.

https://doi.org/10.4103/0970-9290.195618

4. James JM, Puranik MP, Sowmya KR. Dentinal Tubule Occluding Effect of Potassium Nitrate in Varied Forms, Frequencies and Duration: An In vitro SEM Analysis. J Clin Diag Res : JCDR. 2017;11:Zc06zc8.

5. Ashwini S, Swatika K, Kamala DN. Comparative Evaluation of Desensitizing Efficacy of Dentifrice Containing 5\% Fluoro Calcium Phosphosilicate versus 5\% Calcium Sodium Phosphosilicate: A Randomized Controlled Clinical Trial. Contemp Clin Dent. 2018;9: 330-36.

6. Jacobsen PL, Bruce G. Clinical dentin hypersensitivity: understanding the causes and prescribing a treatment. J Contemp Dent Prac. 2001; 2:1-12.

https://doi.org/10.5005/jcdp-2-1-27

7. Pinto SC, Silveira CM, Pochapski MT, Pilatt GL, Santos FA. Effect of desensitizing toothpastes on dentin. Braz Oral Res. 2012;26:41017.

https://doi.org/10.1590/S1806-83242012000500006

8. Lynch MC, Perfekt R, McGuire JA, Milleman J, Gallob J, Amini $\mathrm{P}$, et al. Potassium oxalate mouthrinse reduces dentinal hypersensitivity: A randomized controlled clinical study. J Am Dent Assoc (1939). 2018;149:608-18.

https://doi.org/10.1016/j.adaj.2018.02.027

9. Hall C, Mason S, Cooke J. Exploratory randomised controlled clinical study to evaluate the comparative efficacy of two occluding toothpastes - a 5\% calcium sodium phosphosilicate toothpaste and an $8 \%$ arginine/calcium carbonate toothpaste - for the longer-term relief of dentine hypersensitivity. J Dent. 2017;60:36-43.

https://doi.org/10.1016/j.jdent.2017.02.009

10. Seong J, Parkinson CP, Davies M, Claydon NCA, West NX. Randomised clinical trial to evaluate changes in dentine tubule occlusion following 4 weeks use of an occluding toothpaste. Clin Oral Investig. 2018;22:225-33.

https://doi.org/10.1007/s00784-017-2103-5

11. Haefeli M, Elfering A. Pain assessment. Europ spine J. 2006;15 Suppl 1:S17-24.

https://doi.org/10.1007/s00586-005-1044-x

12. Hong JY, Lim HC, Herr Y. Effects of a mouthwash containing potassium nitrate, sodium fluoride, and cetylpyridinium chloride on dentin hypersensitivity: A randomized, double-blind, placebo-controlled study. J period Implant Sci. 2016;46:46-56.

https://doi.org/10.5051/jpis.2016.46.1.46

13. West NX, Seong J, Davies M. Management of dentine hypersensitivity: efficacy of professionally and self-administered 
Toothpastes in alleviating dentin hypersensitivity following manual scaling

agents. J Clin Periodontol. 2015;42 Suppl 16:S256-302. https://doi.org/10.1111/jcpe.12336

14. Rees JS, Addy M. A cross-sectional study of buccal cervical sensitivity in UK general dental practice and a summary review of prevalence studies. Int J Dent Hygiene. 2004;2:64-9. https://doi.org/10.1111/j.1601-5029.2004.00068.x

15. Karim BF, Gillam DG. The efficacy of strontium and potassium toothpastes in treating dentine hypersensitivity: a systematic review. Int J Dentistry. 2013;2013:573258.

https://doi.org/10.1155/2013/573258

16. Orchardson R, Gillam DG. The efficacy of potassium salts as agents for treating dentin hypersensitivity. J Orofacial Pain. 2000;14:9-19.
17. Porto IC, Andrade AK, Montes MA. Diagnosis and treatment of dentinal hypersensitivity. J oral science. 2009;51:323-32.

https://doi.org/10.2334/josnusd.51.323

18. Kishore A, Mehrotra KK, Saimbi CS. Effectiveness of desensitizing agents. J Endod. 2002;28:34-5.

https://doi.org/10.1097/00004770-200201000-00008

19. Bartold PM. Dentinal hypersensitivity: a review. Aust Dent J. 2006;51:212-8; 76.

https://doi.org/10.1111/j.1834-7819.2006.tb00431.x 